le portiQue $\begin{array}{ll}\text { Le Portique } \\ \text { Revue de philosophie et de sciences humaines }\end{array}$

33 | 2014

Straub !

\title{
Le DVD
}

\section{(2) OpenEdition \\ 1 Journals}

\section{Electronic version}

URL: http://journals.openedition.org/leportique/2782

DOI: 10.4000/leportique.2782

ISSN: $1777-5280$

\section{Publisher}

Association "Les Amis du Portique"

\section{Printed version}

Date of publication: 1 May 2014

ISSN: 1283-8594

\section{Electronic reference}

"Le DVD", Le Portique [Online], 33 | 2014, document 1, Online since 25 April 2014, connection on 12 April 2021. URL: http://journals.openedition.org/leportique/2782 ; DOI: https://doi.org/10.4000/ leportique. 2782

This text was automatically generated on 12 April 2021.

Tous droits réservés 
Le DVD 


\section{Une jeunesse messine}

1 (entretien avec Jean-Marie Straub)

2 Paris, Hôpital Bretonneau, samedi 18 avril 2009

341 minutes, 2013.

4 Renversé par un scooter qui l'a blessé au pied, Jean-Marie Straub était hospitalisé lorsqu'il a accordé un entretien filmé à l'équipe de Ciné-Art.

5 Il évoque ses premiers pas de cinéphile dans sa ville natale (Metz) entre 1949 et 1954, puis ses débuts de cinéaste, notamment le projet de Chronique d'Anna Magdalena Bach (projet de 1954 réalisé en 1962). Il y parle de son refus de la guerre d'Algérie, de sa condamnation et de son exil en Allemagne où commence la carrière « des » Straub.

6 Une seconde partie de l'entretien aborde le devenir de leurs films (la sauvegarde des originaux, les copies) et le projet de Ciné Art d'organiser une rétrospective à Metz.

7 Les vues de Metz en 1955 sont extraites du film Metz pour nous deux de Jean Garnier (avec l'aimable autorisation de la famille Garnier).

\section{Jean-Marie Straub de A à Z}

80 minutes ; 2013

9 Classée par ordre alphabétique, une anthologie des prises de parole de Jean-Marie Straub, lors de la rétrospective Straub-Huillet, en mars-avril 2011 (Centre PompidouMetz, Université de Lorraine, Caméo et autres lieux messins...).

\section{L'entretien de Scy-Chazelles}

28 minutes; 2013. Entretien ayant eu lieu durant la Rétrospective entre Jean-Marie Straub et Benoît Goetz. 